\title{
The mechanism of wearing of the hard alloy tool under ultrasonic reinforcing finishing treatment
}

\author{
Viktor Gileta ${ }^{1, *}$, and Anatoly Beznedelnyy ${ }^{1}$ \\ ${ }^{1}$ Novosibirsk State Technical University, Faculty of Mechanical Engineering and Technologies, \\ 630073 Prospekt K. Marks 20, Novosibirsk, Russia
}

\begin{abstract}
The working capacity of indenters prepared from hard alloy VK8 under conditions of reinforcing finishing treatment by ultrasonic tools was investigated. It was found that under normal treatment conditions, normal wear of the hard alloy takes place. An electron microscopic study of the morphology of the surface of the wear area and its state after the etching of cobalt $(\mathrm{Co})$ using replicas was performed. X-ray microanalysis of the wear area was performed. No obvious traces of adhesive, diffusion, abrasive wear were detected. It was shown that the deterioration of the hard alloy tool VK8 mainly occurs as a result of fatigue failure, which leads in the investigated speed range of the part $10 \ldots 120 \mathrm{~m} / \mathrm{min}$ to the precipitation of individual carbide grains and whole groups of them. The non-linear nature of the wear-velocity curve is due to allotropic transformations of cobalt. It was found that at cobalt speeds of $10 \ldots 50 \mathrm{~m} / \mathrm{min}$, the first allotropic transformation from the initial $\beta$-Co state to $\alpha$-Co occurs, and then the second partial allotropic conversion of $\alpha$-Co to $\beta$-Co occurs at a velocity of more than $50 \mathrm{~m} / \mathrm{min}$. The presence of a $\beta$-Co phase, which is more brittle, leads to an intensification of wear. The WC-WC boundaries and the deformation of WC carbides are not responsible for the formation of the wear surface microrelief and the integral wear of the carbide tool.
\end{abstract}

\section{Introduction}

A hardening-finishing treatment with an ultrasonic tool (ultrasonic treatment) is an effective method of increasing the durability of parts working under conditions of sliding friction, rolling, cyclic loading $[1,2]$. However, the appearance of a wear pad on the indenter (the working part of the tool) leads to a reduction in both the strengthening and smoothing effects. Therefore, the selection of materials that are highly resistant to destruction in the conditions of ultrasonic treatment is an important technological challenge. Rational choice of materials is impossible without revealing the factors that are most influencing the processes of wear and the mechanisms responsible for the destruction of friction surfaces. Therefore, the purpose of the work was to identify the main types of wear that occur in the ultrasonic treatment and the mechanisms responsible for the destruction (deterioration) of the indenter material.

\footnotetext{
* Corresponding author: v.gileta@,corp.nstu.ru
} 


\section{Materials, tools and methods of experimental research}

Wear of indenters in the ultrasonic treatment conditions was carried out by processing the external cylindrical surfaces of inner rings of roller rail bearings made of steel SHX 15. The initial hardness of the rings was HRC $60 \ldots 62$, the roughness $\mathrm{Ra}=0.63 \mu \mathrm{m}$.

The ultrasonic treater included a lathe $1 \mathrm{~K} 62$, a special device, ultrasonic generator UZG2-4, a magnetostrictive transducer PMS 15A-18. To increase the amplitude of oscillations of the instrument, concentrators-waveguides of longitudinal oscillations were used. Indenters were attached to the concentrators by soldering (with brazing solder). The static force of pressing the tool against the part was created by calibrated loads. The amplitude of oscillations of the indenter was determined by the optical method. Wear of indenters was carried out under conditions of propagation of ultrasonic oscillations along the normal to the treated surface.

The technological modes of the ultrasonic treatment in the process of wear were selected from the condition of providing high both strengthening and smoothing effects: static load Pst $=200 \ldots 400 \mathrm{~N}$, tool vibration amplitude $\mathrm{A}=20 \mu \mathrm{m}$, oscillation frequency $\mathrm{f}=$ $18 \mathrm{kHz}$, feed $\mathrm{S}=0,07 \mathrm{~mm} / \mathrm{rev}$, the processing speed changed within the limits $\mathrm{V}=10 \ldots 120$ $\mathrm{m} / \mathrm{min}$, as the cutting fluid oil "Industrial 45 " was used.

The wear of indenters was estimated by the size of the wear site (Fig. 1), which was measured in two directions: the feed and the peripheral speed of the part, the average value was taken into account. The wear pad was measured directly on the machine using a Brinell magnifier with an increase in $\mathrm{x} 24$ and using a special add-on device based on optical system of the PMT-3 micro durometer. The error in measuring by these instruments was $\pm 0.05 \mathrm{~mm}$ and $\pm 0.005 \mathrm{~mm}$, respectively.

The working part of the indenter was made of a spherical shape with a radius of $5 \mathrm{~mm}$. Forming was carried out by electrochemical method, followed by polishing with diamond pastes to $\mathrm{Rz}=0.30 \mu \mathrm{m}$. The deviation of the shape of the profile did not exceed $\pm 0.01 \mathrm{~mm}$.

The morphology of the wear pad was studied using an optical microscope Carl Zeiss Axio A1m and an electron microscope EF-4.

The primary imprint of the wear site was obtained with an acetyl cellulose film. The secondary imprint was created by simultaneous application of carbon and platinum at an angle of $23^{\circ}$ to the contact surface of the primary imprint. Then the primary imprint was dissolved in methyl acetone.

To study the deformation of WC carbides, cobalt was etched from the wear site. Etching was performed by electrochemical method at a voltage equal to $0.35 \mathrm{~V}$ at the potentiostat. The electrolyte was a $15 \% \mathrm{NaCl}$ solution in water, the etching time was $40 \mathrm{sec}$. Slip bands in carbides were detected by chemical etching in the Murokami reagent.

\section{Results and discussion}

The workability of indenters made of ShH15, R6M5, R18, VK2, VK4M, VK8, VK8M, VK15, VK60M, T15K6, T30K4 was investigated. The experiments showed that the highest wear resistance in the ultrasonic treatment conditions is possessed by indenters made from hard alloy VK8.

Fig. 2 shows typical curves of wear-speed of a component of indenters made of hard alloy VK8 under various static loads on the tool. One can see that the curves are not monotonous.

The progress of the external friction processes is influenced by many factors: the kind of friction; the magnitude of the load and the nature of its application; speed of relative slip; medium in which friction of surfaces occurs; structure and properties of materials of 
contacting bodies [3-5]. These factors determine the stress-strain state of the materials of bodies in the friction zone and the nature of their destruction.

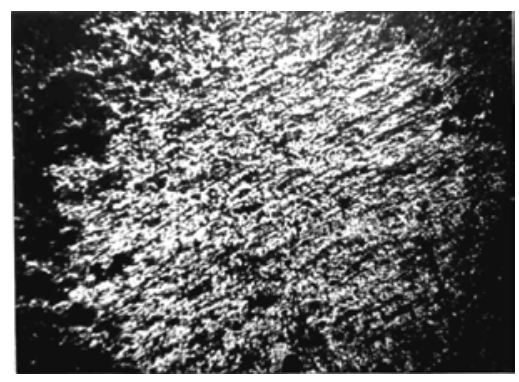

Fig. 1. Wear area

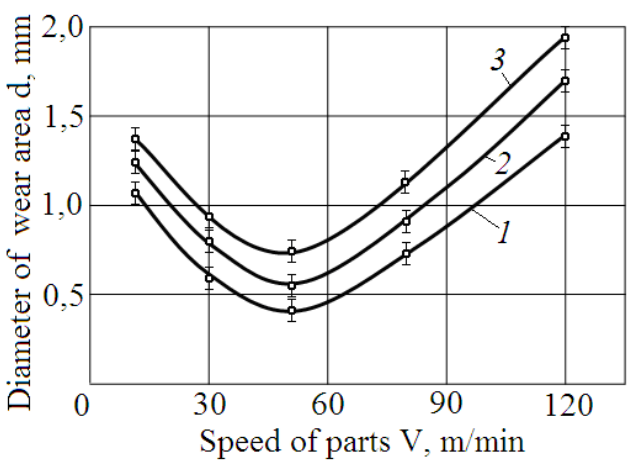

Fig. 2. Wear curves under friction path $\mathrm{L}=1700 \mathrm{~m}$ : $1-$ Pst $=200 \mathrm{~N} ; 2-\mathrm{Pst}=300 \mathrm{~N} ; 3-\mathrm{Pst}=400 \mathrm{~N}$

As a rule, in the process of friction, several types of wear of friction surfaces are simultaneously observed [6], while their contribution to the total wear amount can be both commensurable, and the leading type (types) responsible for the nature and magnitude of wear can be manifested.

Analyzing the conditions of interaction of rubbing surfaces under ultrasonic treatment, it can be assumed that the most characteristic types of wear indenter can be abrasive, cavitation, adhesion, fatigue.

An external manifestation of the abrasive form of wear is the presence in the site of wear of traces of microcutting and (or) furrows, which arise due to plastic deformation of the indenter material by separate free or fixed particles. Optical studies have shown that on the site of wear neither scratches nor furrows are observed. Even if there is separation of particles or grains of WC carbide due to fatigue or other effects in ultrasonic treatment, the cyclic features of the interaction of bodies and flow in the coolant is likely to facilitate their rapid removal from the contact zone. Therefore, the abrasive wear of the indenters made of the hard alloy VK 8 is not characteristic for the ultrasonic treatment.

A study of the role of adhesive wear in the integral wear of a hard alloy was carried out by the presence of a lump of the material of the part on the wear pad. Electron-diffraction and electron microscope studies did not reveal the presence of hardening material at the wear site (Fig. 3). Along with these studies, the chemical composition of the wear pad material was studied using X-ray spectral microanalysis, which showed that the content of tungsten and cobalt and their distribution corresponded to the initial state of the hard alloy VK8, and the intensity of the Fe line on the worn surface corresponded to the background level.

Thus, if there is adhesion of the material of the part and indenter under ultrasonic treatment, the bonds formed are not strong and the destruction occurs at the place of their origin. The invariance of the chemical composition of the worn surface and the surface of the sample speaks in favor of the fact that, under selected regimes of the treatment, diffusion of $\mathrm{Fe}$ into the hard alloy $\mathrm{BK} 8$ and $\mathrm{W}$ and Co into the treated material does not accelerate. Carbon diffusion was not considered in the work. The results obtained allow suggesting that the adhesion and diffusion are not the main mechanisms responsible for integral wear in the ultrasonic treatment. 


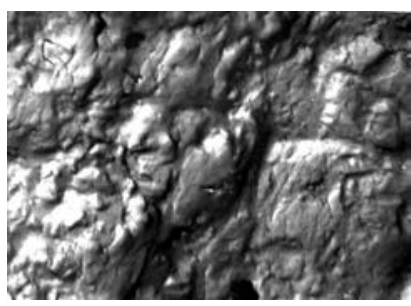

a

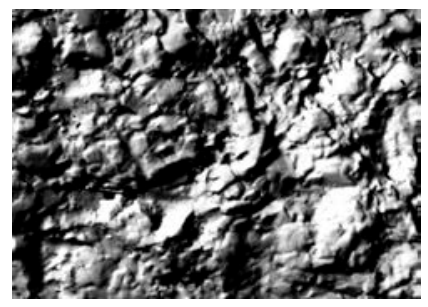

$\mathrm{b}$

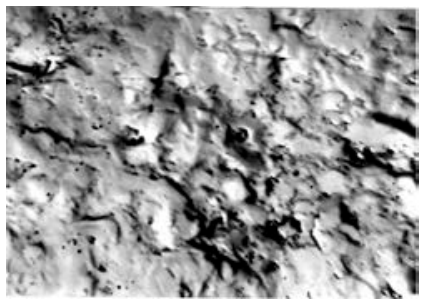

c

Fig. 3. The wear surface of a hard alloy at different parts speed; replica $x 7000: a-V=10 \mathrm{~m} / \mathrm{min}$; $\mathrm{b}-\mathrm{V}=50 \mathrm{~m} / \mathrm{min} ; \mathrm{c}-\mathrm{V}=120 \mathrm{~m} / \mathrm{min}$

One of the types of wear indenters under ultrasonic treatment can be cavitation, since there are conditions for this: the presence of a liquid medium (Industrial 45 oil) and a source of ultrasonic energy-a concentrator-waveguide. In addition, the source of cavitation can be the discharge zones that arise in the flow of a fluid when flowing around surface irregularities.

Studies of the morphology of the surface of indenters from the hard alloy VK8 showed that there are no obvious traces of cavitation destruction at the wear site, although outside the zone of direct contact of the bodies after $20 \ldots .25$ minutes of wear, a matt halo and a girdle are observed. The low intensity of the cavitation processes can be explained by the fact that the oil "Industrial 45" was used as the coolant, which has an increased viscosity, which hinders the development of cavitation. Thus, for the technological modes under consideration, cavitation wear is not essential and cannot be responsible for the integral wear of the indenter from the VK8 hard alloy.

For most solid materials, fatigue is one of the leading types of wear. Further studies were aimed at identifying this type of wear during ultrasonic treatment and its role in the integrated wear of the hard alloy VK8. Studies have shown that with increasing processing speed, differences in the appearance of carbide grains of VK8 alloy are observed. Thus, when $\mathrm{V}=10 \ldots 20 \mathrm{~m} / \mathrm{min}$, the carbides have clear boundaries, when the velocity is increased to $\mathrm{V}=50 \ldots 120 \mathrm{~m} / \mathrm{min}$, the carbides are not clearly identified, they have a rounded shape, flooded boundaries, and sometimes especially at $\mathrm{V}=50 \mathrm{~m} / \mathrm{min}$ surface can only assume that it is carbide. A clear identification of the WC boundaries can be the result of sliding along the WC-Co interface; the lubricated WC boundaries can be, as the microstructure analysis showed, the result of intense plastic deformation of the Co phase and the destruction of the alloy along it. As a result, not clear carbides are visible, but carbides with cobalt remaining on their surface, which closes the boundaries of WC.

Depending on the processing speed, the morphology of the carbides also changes. If at $\mathrm{V}=10-50 \mathrm{~m} / \mathrm{min}$. (the descending part of the curve "wear - the speed of the part") carbides predominate without any traces of destruction, then at $\mathrm{V}=120 \mathrm{~m} / \mathrm{min}$, traces of destruction in the form of pits and chips appear on the WC surface. After the etching of the Co phase, the difference in WC morphology is preserved. Thus, at a velocity $\mathrm{V}=80 \mathrm{~m} / \mathrm{min}$, electrochemical etching of its $15 \% \mathrm{NaCl}$ in water after 5 seconds reveals areas with a sharply heterogeneous character of etching of the Co phase (Fig. 4).

The inhomogeneous character of the electrochemical etching of cobalt in $15 \% \mathrm{NaCl}$ in water may indicate that it is present simultaneously on the wear site in two allotropic states, $\alpha$-Co and $\beta$-Co [7-9]. At velocities $V=10 \ldots 50 \mathrm{~m} / \mathrm{min}$, cobalt has the structure of fcc $(\alpha-$ $\mathrm{Co}$ ), which has good ductility. Then, as the velocity of the part (temperature) increases in some sections, $\alpha$-Co undergoes an allotropic transformation into $\beta$-Co. $\beta$-Co has a hcp structure that is less ductile than that of fcc. Exhaustion of the plasticity of $\beta$-Co as the 
component speed increases above $\mathrm{V}=50 \mathrm{~m} / \mathrm{min}$ leads to intensive destruction of this phase and loss of WC carbides or their groups from the surface of the wear site.

The study of the intergranular boundaries of the WC-WC material of the wear site showed (Fig.5) that they are strong and it is difficult to speak about any displacement of $\mathrm{WC}$ grains relative to each other at Y30. Therefore, it is naturally to assume that WC-WC intergranular sliding cannot be responsible for the formation of the microrelief of the wear site and its destruction.

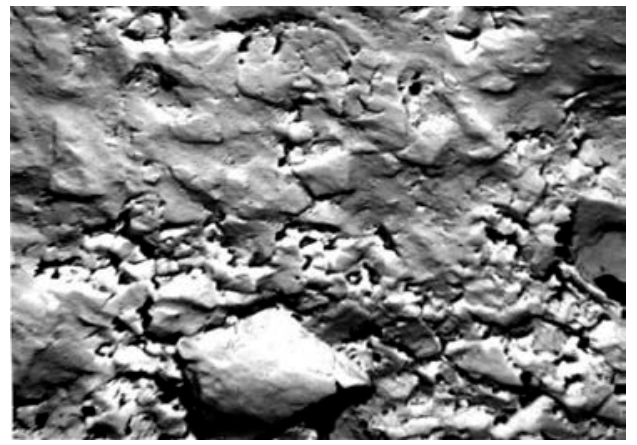

Fig. 4. Inhomogeneous character of Co-phase etching; replica $\times 7000: \mathrm{V}=80 \mathrm{~m} / \mathrm{min}$

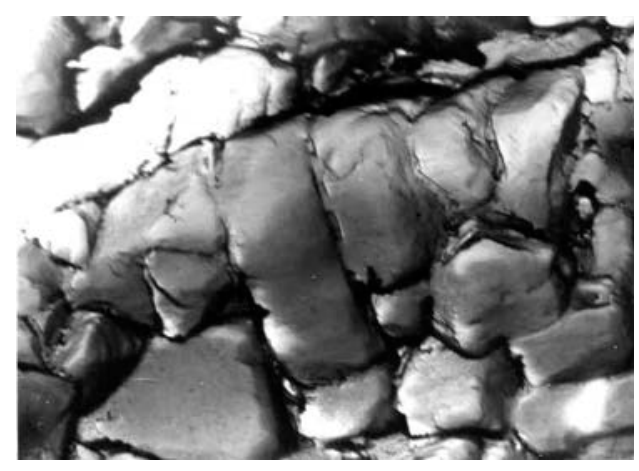

Fig. 5. Intergranular boundary WC-WC; replica $\times 12000$

Simultaneously with plastic deformation of cobalt, there is, albeit a weak, plastic deformation of the carbide grains. It has been established that in the case of RCD only the formation of slip bands occurs in some carbides (Fig. 6). Slipping in WC is detected at speeds $\mathrm{V}=10 \ldots 50 \mathrm{~m} / \mathrm{min}$, the increased development of which is impeded by the high fragility of carbides. With a further increase in speed to $\mathrm{V}=80 \ldots 120 \mathrm{~m} / \mathrm{min}$, slip bands detected by chemical etching in the Murakami reagent were not found, which is probably due to the increase in temperature in the friction zone and the appearance of processes such as polygonization.

Since the slip band even sprouting through the whole crystal is a source of internal stresses, the presence of coarse slip bands and the appearance of fatigue cracks in such a fragile crystal as WC can lead to its fracture by chips (Fig. 7). However, this type of destruction is extremely rare.

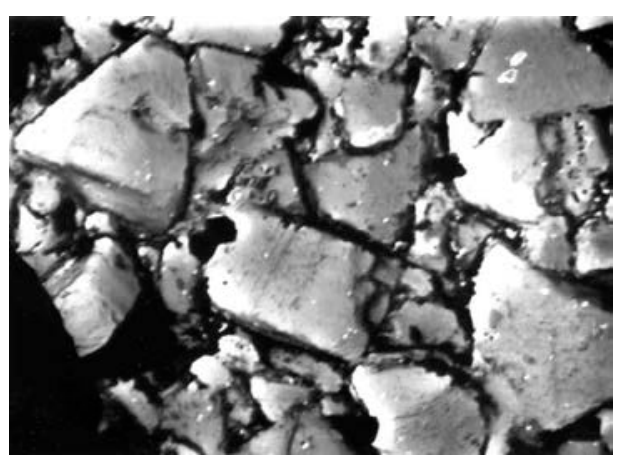

Fig. 6. Slip bands in WC; replica $x 12000$ : $\mathrm{V}=50 \mathrm{~m} / \mathrm{min}$

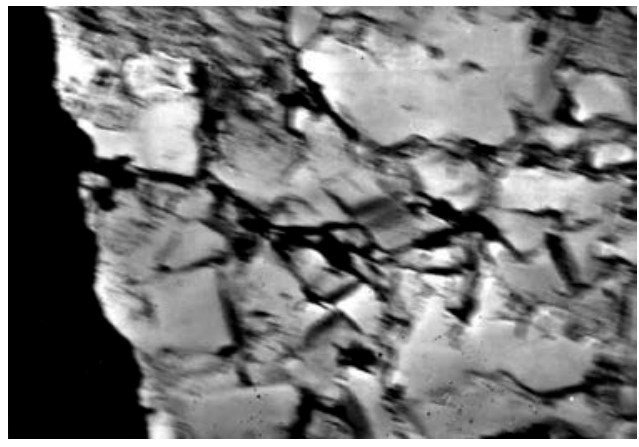

Fig. 7. Destruction of WC carbide along the slip band; replica $\mathrm{x} 12000$ 


\section{Conclusions}

1. With wear of the carbide tool under ultrasonic treatment, a nonmonotonic character of the wear-dependence curve on the speed of the parts is observed.

2. The main mechanism of wear of the hard alloy VK8 with ultrasonic treatment is fatigue; there are no obvious traces of adhesive, diffusion, abrasive wear.

3 . The nonmonotonic character of the dependence of wear on the processing speed is associated with the allotropic transformation of $\alpha$-Co in $\beta$-Co.

4. The destruction of the carbide tool VK8 under ultrasonic treatment occurs at $\mathrm{V}=10$ $\mathrm{m} / \mathrm{min}$, mainly at the WC-Co interface, and then goes into destruction by $\alpha$-Co. Intensification of the destruction of a hard alloy at a velocity greater than $50 \mathrm{~m} / \mathrm{min}$ is associated with its transition mainly to $\beta$-Co. The destruction of WC along slip bands, and also due to the formation of pits, chips, does not make a significant contribution to the wear of the indenter from alloy VK8 at ultrasonic treatment.

\section{References}

1. V.P. Gileta, V.B. Asanov, A.I. Beznedelnyy, Tekhnologicheskiye vozmozhnosti poverkhnostnogo plasticheskogo deformirovaniya s ispolzovaniyem ultrazvukovykh kolebaniy (Technological capabilities of surface plastic deformation using ultrasonic vibrations) Proceedings of the Scientific-practical. Conf. "Engineering of the surface layer of machine parts", Kemerovo, Kuzbass State Technical University pp. 75-79 (2009).

2. Kh.M. Rakhimyanov, Yu.S. Semenova, Tekhnologicheskoye obespecheniye geometricheskikh parametrov kachestva poverkhnosti pri ultrazvukovom plasticheskom deformirovanii (Technological support of geometric parameters of surface quality with ultrasonic plastic deformation) Obrabotka metallov (tekhnologiya, oborudovanie, instrument) $=$ Metal Working and Material Science, 56, pp. 33-36 (2012) (in Russian).

3. V.P. Gileta, A.I. Beznedelnyy, V.B. Asanov, Vybor materialov deformatorov dlya uprochnyayushche-chistovoy obrabotki ultrazvukovym instrumentom (Selection of deformer materials for strengthening finishmachining by ultrasonic tools) Actual problems in machine engineering, No. 2, pp. 163-168 (2015) (in Russian).

4. V.P. Gileta, A.I. Beznedelnyy, V.B. Asanov, Vliyaniye SOZh i prisadok na iznos instrumenta pri ultrazvukovoy uprochnyayushche-chistovoy obrabotke (Cutting fluid and additive effect on the tool wear during ultrasonic strengthening finish machining) Actual problems in machine engineering, No. 2, pp. 158-162 (2015) (in Russian).

5. V.P. Gileta, A.I. Beznedelnyy, V.B. Asanov, Iznosostoykost instrumenta i kachestvo poverkhnosti pri ultrazvukovoy uprochnyayushche-chistovoy obrabotke (Abrasion resistance of the instrument and surface quality with ultrasonic reinforcing finishing treatment) Innovations in mechanical engineering (ISPCIME-2015): Proceedings of the 7th Intern. Scientific-practical Conf., Kemerovo, 23-25 Sept. 2015 - Kemerovo, Kuzbass State Technical University, pp. 77-81 (2015) (in Russian).

6. I.V. Talantov, The physical basis of the process of cutting, wear and tear of the tool. (M.: Mechanical engineering, 1992, 240 p.).

7. I.P. Tretyakov, The fundamentals of metal science and technology for the production of sintered hard alloys. (M.: Metallurgy, 1976, 528 p.).

8. V.A. Falkovsky, L.I. Klyachko, Hard alloys. (M.: Ore and metals, 2005, 416 p.).

9. V.S. Panov, A.M. Chuvilin, V.A. Falkovsky, Technology and properties of sintered hard alloys and products from them. (Moscow: MISIS, 2004, 464 p.). 